\title{
Ovarian carcinoma in normal size ovaries with inguinal lymph node metastasis: a case report
}

\author{
Pankaj Deka ${ }^{1 *}$, Sushruta Shrivastava', Debabrata Barmon'1, Amal Chandra Kataki' and Anupam Sarma \\ *Correspondence: drpankajdeka@gmail.com \\ 'Department of Gynaecological Oncology. \\ ${ }^{2}$ Department of Pathology, Dr. B. Borooah Cancer Institute, Guwahati, Assam, India.
}

\begin{abstract}
It is generally recognized that ovarian cancer tends to remain intra-abdominal even in advanced stages. This case report describes a patient with ovarian carcinoma who had an ulcerated fungating growth in her left groin area.

Case history: A $35 y$ rs para 2 women presented with a fungating left inguinal node of $5 \times 4 \mathrm{~cm}$ for last 3 months. Biopsy revealed metastatic papillary adenocarcinoma. Clinical examination showed left sided pedal oedema. Laboratory investigation revealed increased CA125 (412IU/ml). Radiological studies were normal. In view of the raised Ca 125 she was treated in the lines of FIGO stage III cancer ovary with Paclitaxel 260mg and Carboplatin $450 \mathrm{mg}$ for three cycles. She responded dramatically with completely healedinguinal nodes. Then laparotomy with total hysterectomy, bilateral salpingo-oophorectomy partial omentectomy and inguinal lymph node dissection were performed. Histology confirmed right ovarian adenocarcinoma consistentwith the earlier histology of the left inguinal lymph node. There were noother sites of involvement. Postoperatively, the patient received three more cycle of chemotherapy.

Conclusions: Ovarian cancer with inguinal lymph node metastasis is uncommon and only around $1 \%$ of ovarian carcinoma have a normal sized ovary. This case report demonstrates that early distal metastasis, although rare, can occur in patients with ovarian cancer and may be a compelling symptom of ovarian cancer.
\end{abstract}

Keywords: Ovarian cancer, metastasis, inguinal lymph node, chemotherapy

\section{Introduction}

Ovarian cancer is the most frequent cause of death among the cases of gynaecological cancers $[1,2]$. It represents tumors of epithelial, germ cell or sex cord stromal origin. Approximately $90 \%$ of ovarian tumors are epithelial in origin and poses significant therapeutic challenges as symptoms are more pronounced only in advanced stages. The life time risk of developing sporadic epithelial ovarian cancer is approximately $1.7 \%$, but with familial predisposition, the risk increases to between $10 \%$ and $40 \%$ [3]. There has been a statistically significant improvement in 5 year survival rate of epithelial ovarian cancer over the last decade, from $36 \%$ in 1977 to $45 \%$ in 2002 due to more effective chemotherapy [1].

Generally, ovarian cancer presents itself as disseminated intra-abdominal disease at the time of diagnosis. Primary ovarian lymphatic drainage occurs via the infundibulopelvic ligament to para-aortic nodes. It is traditionally believed that only after its blockage, presumably by tumor emboli, retrograde drainage to pelvic and inguinal node can occur [4]. Also there is a phenomenon called "Normal size ovary carcinoma syndrome" [5] where metastatic disease coexists with ovaries that are grossly normal in size. In about $1 \%$ of cases of ovarian cancer, the ovaries are normal in size $[5,6]$. Our patient was a case of "Normal size ovary carcinoma syndrome" with large metastatic inguinal nodes and without any evidence of disseminated intra-abdominal disease or gross evidence of pelvic or para-aortic lymph node involvement.

\section{Case summary}

On $18^{\text {th }}$ April 2011, we met Mrs. HB, 35 year old and P2L2, who visited our institute complaining of swelling and ulceration in her left groin for the last 3 months. She came to our institute with a fine needle aspiration cytology (FNAC) report of well differentiated papillary adenocarcinoma from the inguinal mass. On clinical examination, we discovered that she had left sided pedal oedema. On further local examination, we found a $4 \times 5 \mathrm{~cm}$ ulcerated fixed fungating growth in the left inguinal region. Per abdominally there was neither any mass felt nor any free fluid. Both the cervix and vagina were healthy, the uterus was anteverted and normal in size, and bilateral fornices were free. We found no abnormality on rectal examination. 


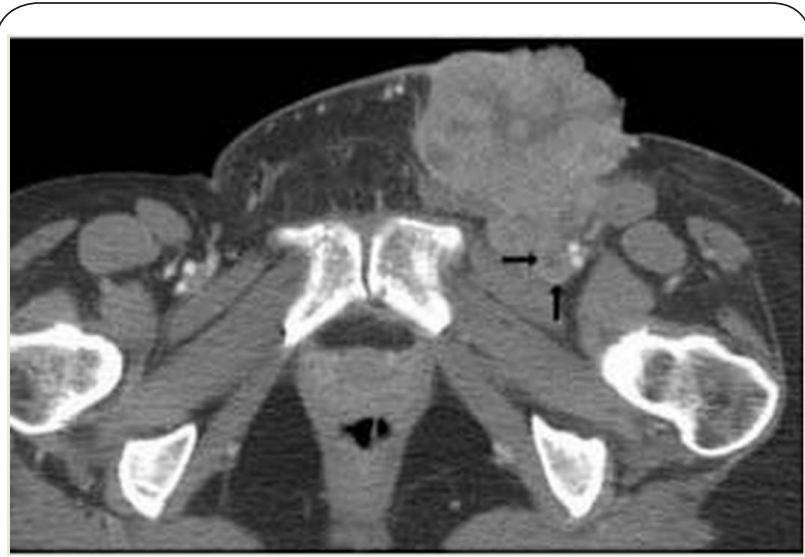

Figure 1. CT Scan showing the metastatic inguinal lymph node.
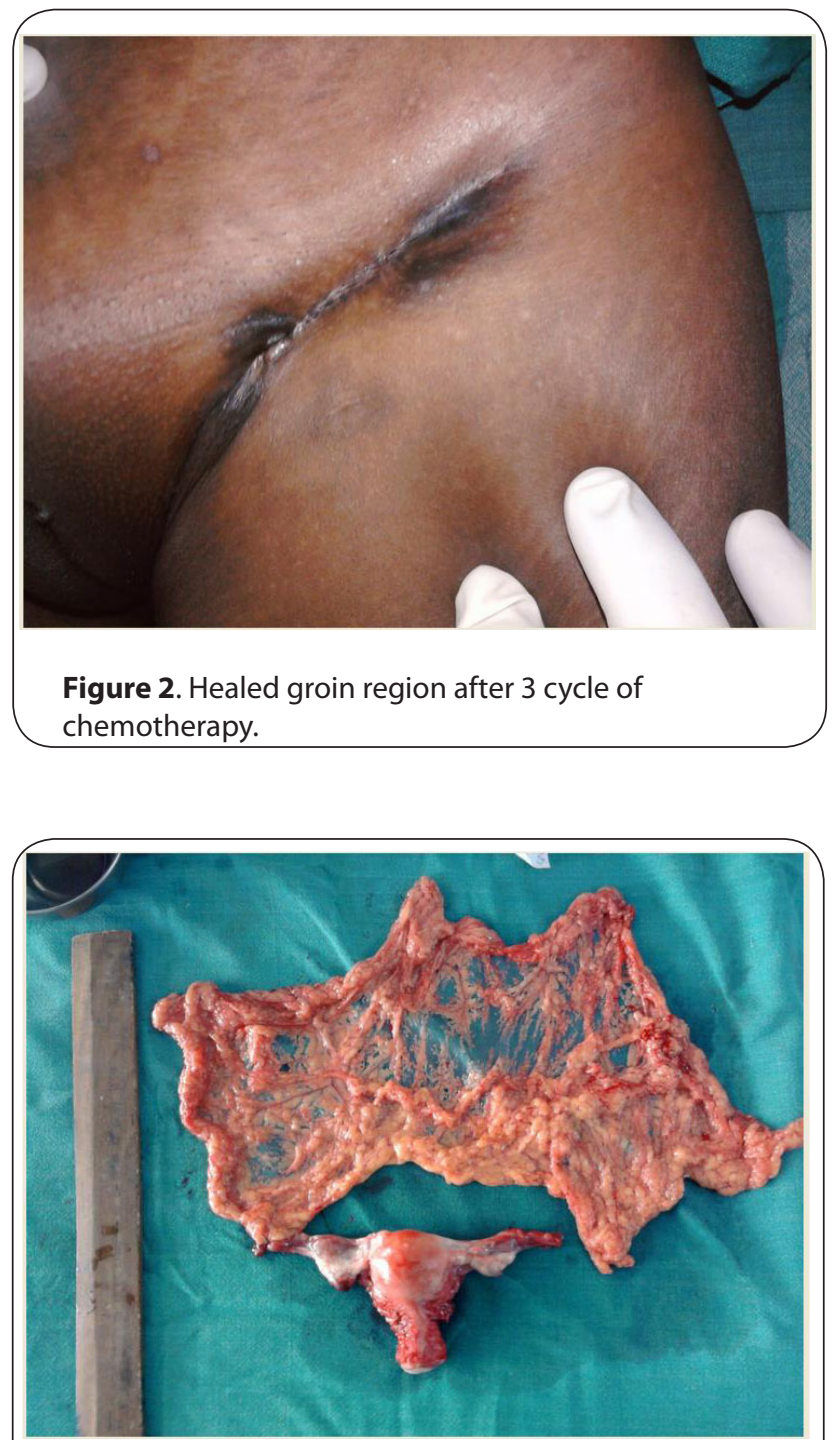

Figure 3. Operative specimen showing normal sized ovaries and uterus.

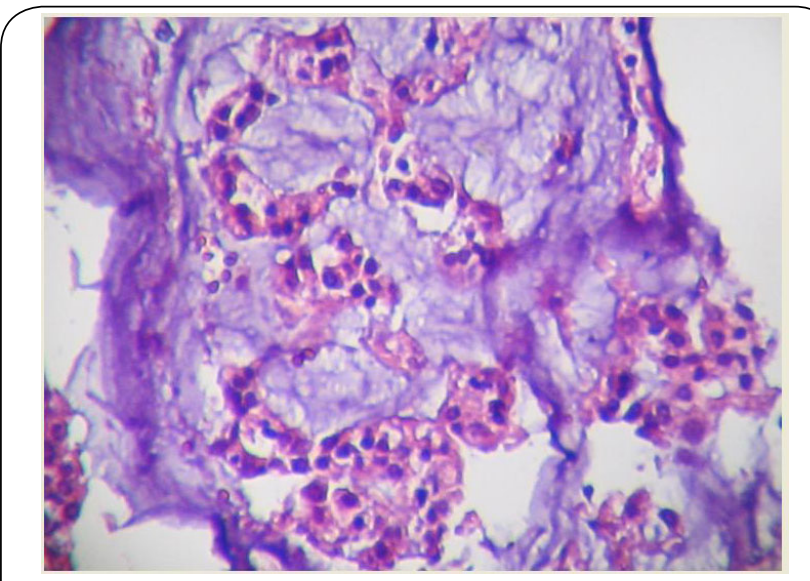

Figure 4. Histopathology of left ovarian specimen showing adenocarcinoma (H\&E 40X).

A computed tomography scan (CT scan) showed multiple conglomerated lymph nodes in the left inguinal region measuring $5 \times 6 \mathrm{~cm}$ in size (Figure 1). Bilateral adnexa and uterus were normal. There was no evidence of any pelvic or paraaortic lymph node and there was no free fluid either. Her upper and lower Gl endoscopy were normal and her serum CA 125 was $412 \mathrm{lU} / \mathrm{ml}$.

At the institute's tumor board meeting, we decided to treat her along the line of ovarian cancer FIGO stage III, in view of clinical, radiological and laboratory findings. We gave her three cycles of paclitaxel $(260 \mathrm{mg})$ and Carboplatin $(450 \mathrm{mg})$. She responded very well to chemotherapy with complete recovery of groin nodes (Figure 2). Exploratory laparotomy showed no evidence of any intra-abdominal tumor and she had a normal sized uterus and ovaries. She underwent total abdomial hysterectomy with bilateral salpingo-oophorectomy, omentectomy and bilateral groin node dissection (Figure 3).

Post-operative histopathology showed foci of well differentiated adenocarcinoma in the left ovary and left groin node specimens (Figure 4). The right ovary, uterus, bilateral tubes, omentum and vaginal cut margin were free of any tumor. In view of the positive histopathology reports, we gave her three more cycles of chemotherapy and completed her treatment on 19th September, 2011. Her post treatment CA125 levels was $5 \mathrm{IU} / \mathrm{ml}$. She is on a regular follow up and is doing well till date.

\section{Discussion}

According to FIGO stage classification for ovarian cancer, lymph node metastasis is classified into stage III ovarian carcinoma. Ovarian cancer with inguinal lymph node metastasis is uncommon. Further, ovarian cancer manifesting as inguinal lymph node metastasis with normal size ovaries is extremely rare. To our knowledge, no such case has been reported till now. D.Ang et al., [7] previously reported a case of a 54 year old lady with a contralateral inguinal node 
swelling and an ovarian tumor measuring $9 \times 6.4 \mathrm{~cm}$ in size. A similar case was reported earlier by Mcgonigle KF and Dudzinshi MR [8] where endometrioid carcinoma of ovary was found with an enlarged inguinal node without any evidence of abdominal carcinomatosis. Mance $\mathrm{N}$ et al., [9] also reported a case in 2006 where ovarian cancer was diagnosed with PET CT scan in a patient with bilateral inguinal lymphyadenopathy as the primary complaint.

A few cases of recurrent ovarian cancer with inguinal lymph node metastasis have been reported by Kohoe et al.,[10]. Brett A Winter-Roach et al., [11] reported a case of fallopian tube cancer with inguinal lymph node metastasis. Makoto et al., [12] reported a case of mucinous cyst adenocarcinoma with normal sized ovaries with elevated CA 19.9 levels $(3483 \mathrm{U} / \mathrm{ml})$ and normal CA $125(28 \mathrm{U} / \mathrm{ml})$.

The most common way in which epithelial ovarian cancer spreads is by transcoelomic spread to adjacent viscera [1]. Lymphatic drainage of the ovary follows its blood supply through the infundibulopelvic ligament to nodes of paraaortic region, but can also occur through the broad ligament and parametrial channels to external iliac,obturator and hypogastric chains. Rarely, epithelial ovarian cancer may also spread along the course of round ligaments resulting in involvement of inguinal lymph nodes [2]. Autopsy studies have reported inguinal metastasis in $0-3 \%$ of patients with advanced disease [3]. The third and least common way of ovarian cancer spreading is through the haematogenous route and occurs in 2-3\% of patients. Distal organs and contralateral ovary may be involved in this manner.

Our case is an unusual occurrence of ovarian cancer, with normal sized ovary and no evidence of any intraperitoneal disease. The only visible feature was inguinal lymph node enlargement. Yet, we have to consider this as a stage IIIC disease. The impact of such clinical presentation on prognosis is unknown and no previous study has been reported on it.This case demonstrates that early distal metastasis, although rare, can occur in patients with ovarian cancer and may be a symptom to look out for when diagnosing ovarian cancer.

\section{Competing interests}

The authors declare that they have no competing interests.

Acknowledgement

I would like to thanks Mrs. Suruchi Saxena and Mr. Govind

Bansal for their kind support in editing the article.

Publication history

Received: 2-Dec-2012 Revised: 12-Dec-2012

Accepted: 31-Dec-2012 Published: 19-Jan-2013

\section{References}

1. Jemal A, Siegel R, Ward E, Murray T, Xu J and Thun M J: Cancer statistics, 2007. CA Cancer J Clin 2007, 57:43-66. | Article I PubMed

2. Tayfun G, Burcin S, Mustafa O, Ozlem A, Omer L, leyla M. Turkish. Isolated Inguinal lymph node metastasis; presenting in ovarian cancer in an unexpected case of relapse : a case report. J of Gynecologic oncology, June 2009-4, Pg 97-100.

3. Cannistra S A: Cancer of the ovary. N Engl J Med 2004, 351:2519-29. | Article I PubMed

4. Scholz H S, Lax S, Tamussino K F and Petru E: Inguinal lymph node metastasis as the only manifestation of lymphatic spread in ovarian cancer: A case report. Gynecol Oncol 1999, 75:517-8. | Article | PubMed

5. Feuer G A, Shevchuk $M$ and Calanog A: Normal-sized ovary carcinoma syndrome. Obstet Gynecol 1989, 73:786-92. | Article | PubMed

6. Berek JS, Hacker NF, editors. Practical Gynecologic Oncology. Lippincott Williams and Wilkins (3rd ed.), Philadelphia 1994:466-7.

7. Ang D, Ng K Y, Tan H K, Chung A Y, Yew B S and Lee V K: Ovarian carcinoma presenting with isolated contralateral inguinal lymph node metastasis: a case report. Ann Acad Med Singapore 2007, 36:427-30. | PDF | PubMed

8. McGonigle K F and Dudzinski M R: Endometrioid carcinoma of the ovary presenting with an enlarged inguinal lymph node without evidence of abdominal carcinomatosis. Gynecol Oncol 1992, 45:2258. | Article | PubMed

9. Manci N, Bellati F, Graziano M, Pernice M, Muzii L, Angioli R and Benedetti Panici P: Ovarian cancer, diagnosed with PET, with bilateral inguinal lymphadenopathy as primary presenting sign. Gynecol Oncol 2006, 100:621-2. | Article | PubMed

10. Kehoe $S$, Luesley $D$ and Rollason $T$ : Ovarian carcinoma presenting with inguinal metastatic lymphadenopathy $\mathbf{3 3}$ months prior to intraabdominal disease. Gynecol Oncol 1993, 50:128-30. | Article | PubMed

11. Winter-Roach B A, Tjalma W A, Nordin A J, Naik R, de Barros Lopes $A$ and Monaghan J M: Inguinal lymph node metastasis: an unusual presentation of fallopian tube carcinoma. Gynecol Oncol 2001, 81:324-5. | Article | PubMed

12. Emoto M, Fujimitsu R, Iwasaki $H$ and Kawarabayashi T: Diagnostic challenges in patients with tumors: case 3 . Normal-sized ovarian cancer detected by color doppler ultrasound using a microbubble contrast agent. J Clin Oncol 2003, 21:3703-5. | Article | PubMed

\section{Citation:}

Deka P, Shrivastava S, Barmon D, Kataki AC and Sarma A: Ovarian carcinoma in normal size ovaries with inguinal lymph node metastasis: a case report. journal of Cancer Therapeutics and Research 2013, 2:3. http://dx.doi.org/10.7243/2049-7962-2-3 